\title{
Study on countermeasures of the maintenance spares storage based on AHP
}

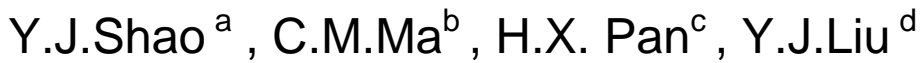 \\ Shanxi Advanced Manufacturing Technology Laboratory, North University of China, Shanxi \\ 030051, China \\ asyjbkd@163.com, ㄹmachm@vip.163.com, cpanhx1015@163.com, ${ }^{\mathrm{d} I y j 70901 @ n u c . e d u . c n ~}$
}

Keywords: spare parts, AHP, importance degree, classification reserve

\begin{abstract}
Spare parts management is an important part of the maintenance activities and the spare parts are the basic guarantee of maintenance. Classified Management of spare parts is an important issue in the management of spare parts. Only classifying the spare parts scientifically that the maintenance tasks can be completed economically and on time. In the paper, AHP and the importance principle were used to establish the model for classified storage of spare parts. Then a comprehensive index that the importance of the spare parts was used to classify the maintenance spares so that reserving a reasonable amount of the spare parts. Finally, a specific example was used to show the practicability of the method.
\end{abstract}

\section{Introduction}

With the extensive application of high technology in a variety of devices, the complexity of the device as well as the role and place of the supply of spare parts are increasing. While the intermittent and random demand for spare parts is shown. So scientific classification reserves of spare parts is the premise of ensuring the normal operation of equipment [1,2]. Now most commonly used method for classifying reserve of the spare parts is the ABC classification, also known as the Pareto classification, whose basic idea is using qualitative and quantitative analysis to classify the spare parts into $\mathrm{ABC}$ three categories according to the classification indicators, and then taking the appropriate storage policies. The $\mathrm{ABC}$ classification is helpful to distinguish the key point and the normal point, so it was widely used. However, its defect is obvious due to its classified only according to the amount of the varieties and price [3]. Another commonly used classification for spare parts distinguish important parts and accessories in general based on the degree of urgency $[4,5]$. However, it mainly relies on subjective judgments, so it is very difficult to determine the urgency degree of a spare part in many cases[6]. Therefore, AHP was used in the paper to model and research on spare parts management. Due to its characteristic of combination of qualitative and quantitative to treat various decision factors and advantages of flexible and concise, AHP has been widely appreciated and applied in all fields of social economy $[7,8]$.

\section{Steps of evaluating the importance degree of the maintenance spares}

(1) Firstly, using AHP establishes the hierarchy model. The model is shown in Fig.1:

(2) Constructing Judgement Matrix, hierarchy single fanking and its uniformity inspection were carried out simultaneously.

During the Analytic Hierarchy Process, for making each elements of importance was showed quantitatively in the judgment matrix. (1 9) scale method of Constructing judgment matrix in AHP are introduced. Hierarchy single fanking and its uniformity inspection were carried out using MATLAB software simultaneously, Judgement Matrix was showed in the tables.1. 


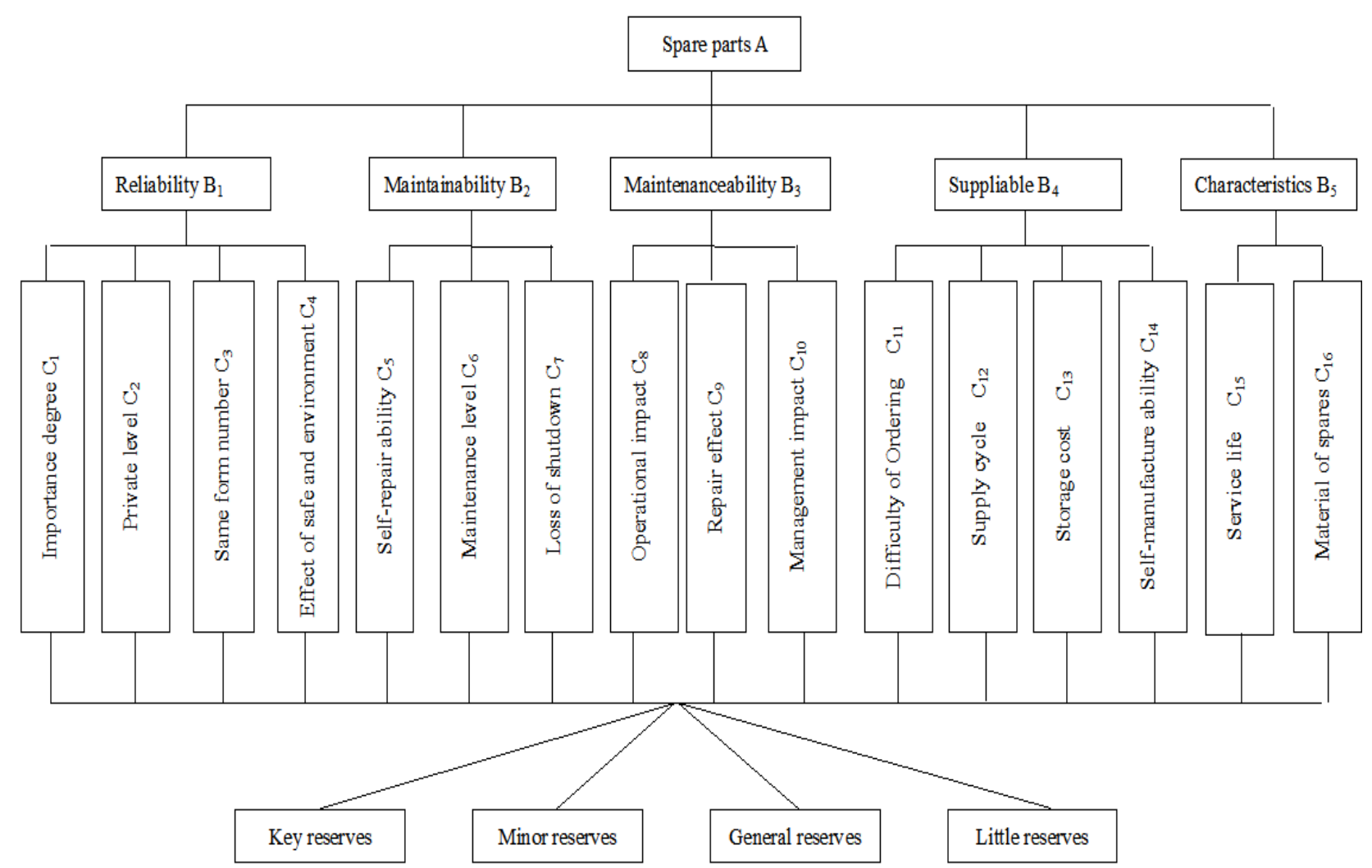

Fig.1 the hierarchy model

tables.1 Judgement Matrix

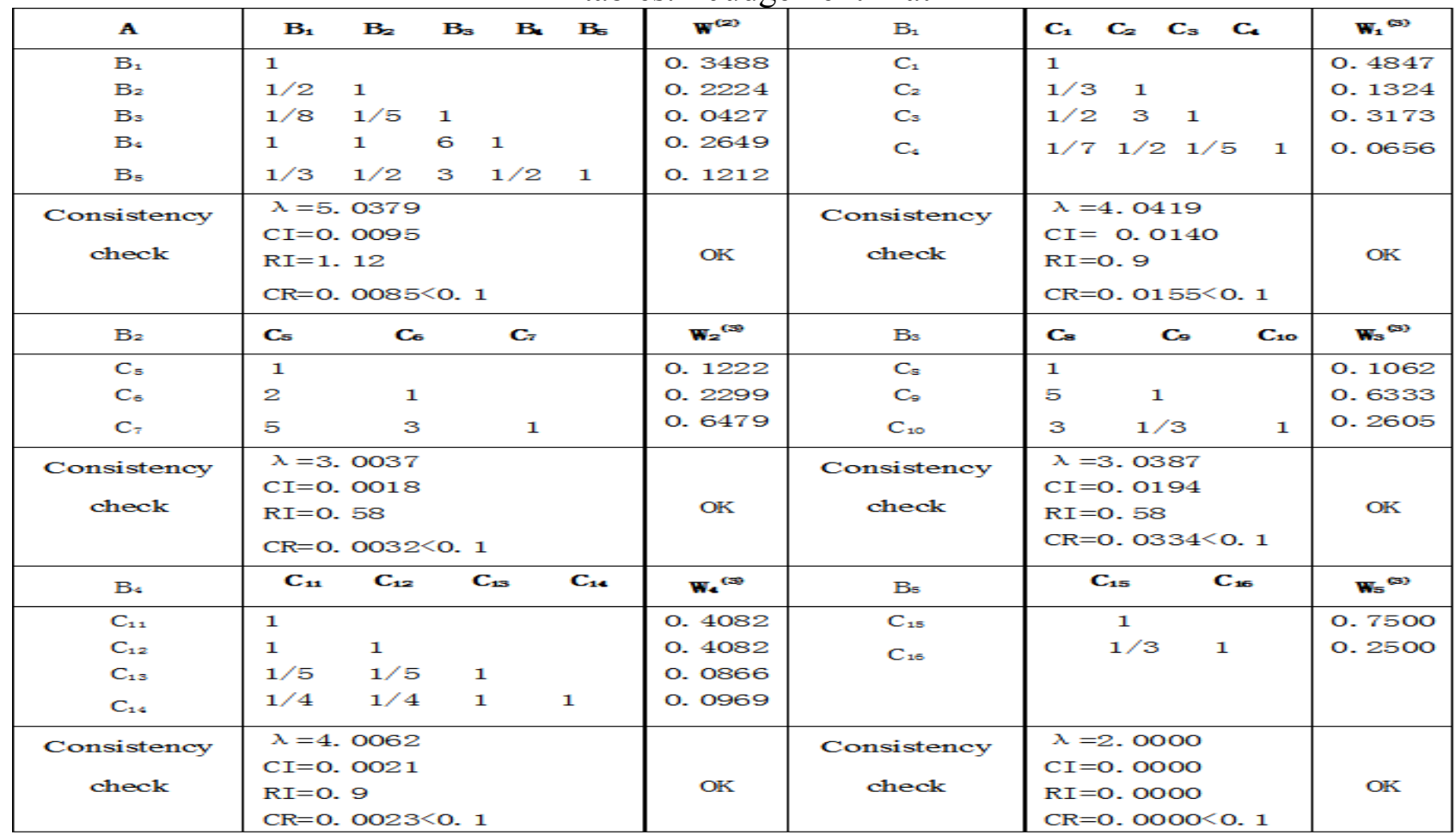

(3) Hierarchy general ranking,

Column vectows ${ }_{k}^{(3)}$ Constitution for $W^{(3)}=\left(W_{1}^{(3)}, W_{2}^{(3)}, W_{3}^{(3)}, W_{4}^{(3)}, W_{5}^{(3)}\right)$, weights of C layer element can be shown in the tables.2.

$$
\begin{aligned}
& W=W^{(3)} W^{(2)} \\
& C I=\sum_{j=1}^{m} b_{j} C I_{j}=0.0067 \quad R I=\sum_{j=1}^{m} b_{j} R I_{j}=0.7061 \quad C R=0.0094<0.1
\end{aligned}
$$


tables.2 weights of C layer element

\begin{tabular}{|c|c|c|c|c|c|c|c|}
\hline C layer & \multicolumn{7}{|c|}{ weights of C layer $(\%)$} \\
\hline$C_{1}$ & 16.9063 & $C_{5}$ & 2.7177 & $C_{9}$ & 2.7042 & $C_{13}$ & 2.2940 \\
\hline$C_{2}$ & 4.6181 & $C_{5}$ & 5.1130 & $C_{10}$ & 1.1123 & $C_{14}$ & 2.5669 \\
\hline$C_{3}$ & 11.0674 & $C_{7}$ & 14.4115 & $C_{11}$ & 10.8132 & $C_{15}$ & 0.0909 \\
\hline$C_{4}$ & 2.2881 & $C_{5}$ & 0.4535 & $C_{12}$ & 10.8132 & $C_{15}$ & 0.0303 \\
\hline
\end{tabular}

(4)How to determine evaluation value of index of maintenance spare parts

Scoring to evaluation value of index of maintenance spare parts in accordance with maintainability、

reliability maintenance、supplying、own characteristics and so on.Score was evaluated by major person liable of the application, maintenance, managers according to $1 \sim 5$.

(5)Importance of spare parts

weights of each index can be obtained by AHP, Importance of spare parts can be obtained by the product of weight and evaluating values of index. The calculating formula of Importance of spare parts is:

$$
B Z D=\sum X_{i j} Y_{i j}
$$

BZD - Importance of spare parts;

$\mathrm{X}_{\mathrm{ij}}$ - evaluation of estimate of Spare parts varieties;

$\mathrm{Y}_{\mathrm{ij}}$ - weight of Spare parts varieties;

Spare parts nature characteristic was evaluated by BZD index as follow in the tables.3:

tables.3 evaluation form of spare parts nature characteristic

\begin{tabular}{|c|c|c|c|c|}
\hline BZD grade & $3.75 \leqslant \mathrm{BZD} \leqslant 5$ & $3.25 \leqslant \mathrm{BZD} \leqslant 3.75$ & $2.75 \leqslant \mathrm{BZD} \leqslant 3.25$ & $2.25 \leqslant \mathrm{BZD} \leqslant 2.75$ \\
\hline $\begin{array}{c}\text { Spare parts nature } \\
\text { characteristic }\end{array}$ & Key reserves & Minor reserves & General reserves & Little reserves \\
\hline
\end{tabular}

\section{Instance analysis}

To verify this method is a kind of effective method by a example of bearing spare parts in service maintenance shop. Firstly, to determine evaluation of estimate of maintenance spare parts through expert scoring, evaluation of estimate of bearing spare parts is shown in the tables.4. then to calculate BZD value of bearing spare parts.

$$
B Z D=\sum X_{i j} \cdot Y_{i j}=2.47
$$

spare parts of bearing belong to maintenance and repair parts of Little reserves because of $2.25 \leq 2.47 \leq 2.75$, To achieve the purpose of classification of maintenance spare parts.

tables.4 evaluation of estimate of bearing spare parts

\begin{tabular}{|l|l|l|l|l|l|ll|l|l|l|l|l|l|l|l|}
\hline $\mathrm{C}_{1}$ & $\mathrm{C}_{2}$ & $\mathrm{C}_{3}$ & $\mathrm{C}_{4}$ & $\mathrm{C}_{5}$ & $\mathrm{C}_{6}$ & $\mathrm{C}_{7}$ & $\mathrm{C}_{8}$ & $\mathrm{C}_{9}$ & $\mathrm{C}_{10}$ & $\mathrm{C}_{11}$ & $\mathrm{C}_{12}$ & $\mathrm{C}_{13}$ & $\mathrm{C}_{14}$ & $\mathrm{C}_{15}$ & $\mathrm{C}_{16}$ \\
\hline 4 & 1 & 5 & 4.5 & 2.5 & 4 & 4 & 3 & 3 & 3 & 2.5 & 1 & 4 & 2 & 2 & 1.5
\end{tabular}

\section{Conclusion}

The paper combined with the actual conditions of the equipment and spare parts management in enterprises, AHP that combined qualitative and quantitative analysis is used in evaluating the importance degree of spare parts. So classified reserve solutions are obtained. Finally, a specific example proved the practicability of the method. It can increase the validity and accuracy of the evaluation for the importance of spare parts. Consequently, the method can play a role of guiding in production and maintenance in the enterprise. 


\section{Acknowledgements}

This work are supported by the National Natural Science Foundation (51175480) and the Shanxi Natural Science Fund Committee(2012011046-12)

\section{References}

[1] H.L.Cheng, et al.Spare parts model under the constraint of fill rate. Systems Engineering and Electronics, Vol.29(2007),p.1314-1316.

[2] X.H.Chen, et al .Ordering policy of spare parts for preventive maintenance of multi-component system Cycle .Journal of South ChinaUniversity of Technology, Vo.137(2009),p.95-99.

[3] M.Zhao.A thesis submitted in partial fulfillment of the requirementsor the Degree of Master of Management Science and Engineering .Research on the Inventory Mode and the Control Policy of Spare Parts. p.15-25.

[4] Dekker R,Kleijn M J.A Spare Parts Stocking PolicyBased on Equipment Criticality. International Journal of Production Economics, 1998,56(3): 69-77.

[5] Fortuin L,Martin H.Control of Service Parts. Inter-national Journal of Operations \& Production Manage-ment,1999,19(9): 950-971.

[6] X.F.Zhao,et al.the model of Quantitative analysis apply in the repair parts inventory controling.Chinese Mechanical Engineering.Vol.15(2004),p.824-827.

[7] Yun-Quan Hu, Yao-Huang Guo. Operations research tutorial. Version 2. Beijing: Tsinghua University Press, $2004.436 \sim 440$.

[8] Qi-zong Wu. Operations research and optimization methods: Machinery Industry Press, 2003. $215 \sim 227$. 